\title{
Lexical Inferencing Strategies for Dealing with Unknown Words in Reading-A Contrastive Study between Filipino Graduate Students and Chinese Graduate Students
}

\author{
Qiaoying Wang \\ Foreign Languages Departments, Bijie University, Bijie, Guizhou, China \\ Email: Qiaokingyx@yahoo.com.cn
}

\begin{abstract}
This study examined the lexical strategies used by EFL learners and ESL learners when they encountered unknown words while reading. It aimed to explore the following research questions: 1. Do Chinese the graduate students and the Filipino graduate students employ lexical inferencing to deal with unknown words in reading? 2. What lexical inferring strategies do the Chinese graduate students and the Filipino graduate students use to deal with unknown words in reading? 3. Is there any difference in the employment of inferring strategies between the Chinese graduate students and the Filipino graduate students? If yes, what is the difference? 4. Do lexical inferring strategies lead to incidental vocabulary learning? The results of this study provided positive answers to all the questions except for no further evidence for gaining new vocabulary incidentally by lexical inferencing strategies. This research produces a new insight into the impact of lexical inferencing strategies on vocabulary learning and offers some suggestions to pedagogic vocabulary practice.
\end{abstract}

Index Terms - lexical inferencing strategies, unknown words, incidental vocabulary learning

\section{INTRODUCTION}

Reading comprehension is regarded as both a process and a product of communication with a writer. To achieve successful reading comprehension, a reader needs "a variety of highly flexible process called comprehension strategies" (May, 2001, p. 119). Vocabulary development is considered as one of the important strategies in reading comprehension (Nagy, Herman, \& Anderson, 1985; Nation \& Coady, 1988; Stoller \& Grabe, 1993). It is commonly agreed by teachers and researchers that vocabulary knowledge and reading have a close relationship. A reader who has much vocabulary knowledge can comprehend a text better. Limited lexical knowledge discourages reading and, simultaneously, a lack of reading restricts vocabulary growth (Coady, 1997). "The higher the academic level, the greater the vocabulary mastery needed" (Paribarht, \& Wesche, 1999, p. 196). To become a successful, advanced reader, a learner will need to learn to use different strategies to deal with unknown words encountered in reading. Generally, a good reader has appropriate strategies to deal with unknown words in reading such as guessing or inferring the meaning of unknown words in a text. Therefore lexical inferencing strategy plays an important role in dealing with unknown words encountered in reading. Since more and more teachers and researchers have come to understand the role of the lexicon in language learning and communication, a great number of researches have been conducted on lexical inferrencing and vocabulary development. Such researches contain studies on the positive effect of the lexical inference strategies on reading comprehension and problems in inferring the meanings of vocabulary from context.

\section{A. Positive Effect of Lexical Inferences on Reading Comprehension}

Inferencing is defined as a cognitive process that utilizes "familiar attributes and contexts" to recognize something unfamiliar in reading (Paribarht, \& Wesche, 1999, p. 198). Lexical inferencing refers to the process of "making informed guesses as to the meaning of a word in light of all available linguistic cues in combinations with the learner's general knowledge of the world, her awareness of context and her relevant linguistic knowledge" (Haastrup, 1991, p. 40). In return, "well-elaborated semantic knowledge, which includes developing knowledge of usage, collocations and other lexico-grammatical characteristics", is primarily gained through learning words by inferring strategies in reading (Hunt, \& Beglar, 2005, p. 28). Huckin and Bloch (1993) conducted an exploratory study; using think-aloud protocols to investigate the inferring strategies by three intermediate NNs graduate students when they encountered unfamiliar words in their course reading comprehension. The study discovered that context clues, especially local ones were the main inferring strategies that students successfully used in solving unknown words. It also found that the reason why the students got unsuccessful guessing was that students wrongly assumed that they knew the word. The three participants were observed to use the same strategies to deal with each word they encountered: first, they brought the meaning of the word that assumed to be known into the reading comprehension without checking the context clues, 
which sometimes led to misinterpretation of the words that had other meanings. Second, they often guessed the meaning of a word by using morphological analysis, combining with context clues in the text if they knew part of the word. Third, they used context clues to make the guess of a completely unknown word. It was notable that this study was conducted "under the presumption that a complete context was provided to infer the meaning of the 'unknown' word" (Roskams, 2005, p. 68). The same results were found in Chern's study (1993), the participants utilized local clues to successfully guess the meaning of the new words. In Johnson \& Yau's study (1996, see Roskams, 2005, p. 69), they also used think-aloud, but the text is much difficult because $70 \%$ of the words were new words to the participants. The participants were Chinese (Cantonese) and were observed to use "a top-down lexical processing survival strategy" to guess the unknown words. The participants were found to "make wild guesses for unknown words" without any attempt to check their understanding of these words from further context clues. DeBot, Paribakht and Wesche (1997) carried out an introspective study to observe how readers dealt with unknown words they encountered while reading. The participants were 10 intermediate ESL learners in Quebec. The study displayed that the participants ignored about half the assumed unknown words, focusing mainly on content words (nouns, verbs and adjectives) and the participants were found to use sentence level grammatical knowledge, word morphology and punctuation. Very few participants used discourse level clues. Paribakht and Wesche (1999) conducted another introspective study to identify the strategies and the kinds of knowledge and information that readers may use to handle the new L2 words they came across during reading and explored the process leading to expansion of vocabulary knowledge through reading. The participants were 10 intermediate-level students in a university ESL class with different L1 backgrounds (Chinese, French, Spanish, Vietnamese, Farsi and Arabic). The results of this study demonstrated that the participants applied different strategies to inferring word meanings from a variety of clues such as synonym, collocation, etc. in a text and other ones like prior knowledge, world knowledge. The participants were observed to mainly use sentence-level grammatical knowledge in lexical inferencing, and sometimes combining with word morphology, punctuation and world knowledge. Notable individual differences in the knowledge sources appeared in this study may be due to "the individual's previous L2 learning experience, their L1 and their familiarity with the text topic" (Paribakht \& Wesche 1999, p. 214). Their study also provided new insights and understanding of incidental vocabulary learning.

\section{B. Problems of Lexical Inferences in Reading}

In Hirsh and Nation's study (1992), even though for less proficient learners, enlarging vocabulary through inferring unknown word meaning can be achieved by explicit instruction and learning, they discovered that too many unknown words prevented participants from inferring vocabulary from context successfully. They drew a conclusion from their study that in an authentic text, for less proficient EFL learners, a very limited frequency vocabulary may lead to the failure of inferring the meanings of unknown words. Carnine, Kameenui, and Coyle (1984) and Haynes (1984) explained that the closeness, the clearness of relevant clues and their degree of concreteness determine correct lexical inferences. When a text does not supply clear and enough clues for unknown words, it is very hard for readers, particularly for less proficiency readers, to figure out the unknown word meaning. Fukkink, Blok, and De Glopper (2001) also stated that partially and completely incorrect inferences may happen if a text does not supply readers with enough information and context for the unknown words; readers do not have prior knowledge or world knowledge of the topic; if there is more than one interpretation of one unknown word which makes readers difficult to determine its meaning, and if readers can not use the strategy of morphological and syntactic clues. Nation (2001) emphasized that the reoccurrence of an unknown word in different contexts without the help of the other relevant clues can influence readers on correctly inferring the meaning of an unknown word.

\section{Classification Type of Lexical Inferencing}

The examination of lexical inferencing often needs to consider the following two aspects. One is using linguistic and other knowledge to infer the unknown words; the other is using the cognitive processes to infer the meaning of new words. Actually, it is difficult to separate the knowledge and process in that "although serial hypothesizing, guessing and decision-making processes seem to be governed by conscious decision making and can be followed in a think-aloud protocol, many generation and recognition activities are relatively unanalysable, because they are unconscious and possibly parallel processes and therefore readers are not able to report them" (Roskams, 2005, p. 71). The following is the parameters used in the lexical inferencing study (adapted from Roskams, 2005, pp, 71-72):

1. INITIAL IDENTIFICATION (Recognition processes)

Word visual recognition: (categories include: no recognition, assume recognize form but forgotten or never knew the meaning, assume recognize form and know meaning)

\section{STRATEGIC RESPONSES}

Analysis of relevant information, synthesis of a working definition including selective updating of previous knowledge. The sources of analysis can be inferred in many cases as follows:

Guess using extra textual (thematic or world) knowledge

Guess using discourse context i.e. outside the sentence in which the word occurred (using forward or backward context)

Guess using local (sentence level) context

Guess using association or collocation knowledge (i.e. a clue word) 
Guess using syntactic knowledge

Guess using visual form (similarity or morphological understanding)

Guess using phonological similarity

All the previous studies presented above seemed to explore effectiveness of lexical inferencing strategies used in dealing with unknown words on the L2 vocabulary acquisition. Few studies have reached the comparison of the lexical inferencing strategies employed by readers from different L1 background in English reading. Therefore this study aimed to investigate the inferring strategies that the Chinese graduate students and the Filipino graduate students employed to deal with unknown words they encountered while reading. This present study sought to explore the following research questions:

1. Do the Chinese graduate students and the Filipino graduate students in this study employ lexical inferencing to deal with unknown words in reading?

2. What inferring strategies do the Chinese graduate students and the Filipino graduate students use to deal with unknown words in reading?

3. Is there any difference in the employment of inferring strategies between the Chinese graduate students and the Filipino graduate students? If yes, what is the difference?

4. Do inferring strategies lead to incidental vocabulary learning?

\section{METHOD}

\section{A. Participants}

Thirty-four (34) graduate students were involved in this study. Of the 34 participants, 17 were Filipino graduate students pursuing Master Degree of Teaching English Language at College of Education, De La Salle University at the time of this study. The other 17 students were Chinese graduate students studying at different colleges, in De La Salle University and University of Philippines. Most of them were studying at De La Salle University and only one was at University of Philippines when the study was conducted. Eleven (11) out of 17 Chinese students were also pursuing Master Degree of Teaching English Language, two MBA, another two Science in Information Technology, one Computer Science and another Environmental Science and Ecological Management. The years that they had been exposed to English ranged from 7 years to 25 years.

\section{B. Material}

The material used in this study was a task sheet, the purpose of which was to examine the lexical inferencing strategies and to obtain some information of incidental vocabulary learning. It contained an article and a post quiz. The article was a 240-word text adapted from Roskam's study (2005). Twelve (12) words were underlined for the purpose of examining the strategies for the unknown words. Before the study, the text with the 12 words underlined were given to 10 Chinese graduate students studying Teaching English Language to identify that these words would be more likely to be unknown words and they confirmed that they knew most of the words except for the twelve underlined words. The 12 underlined words fell into three categories of part of speech: nouns, verbs and adjectives. These words were selected in that the discourse context provides enough clues for the students to infer the meanings of these words even though they could not understand the text or had not any prior knowledge about it. The repetition of the target words were all underlined for the purpose of examining whether the repetition could help the students infer the meanings of the unknown words and whether it could aid them to learn these words from the text. Two of target words appeared twice in the text and one appeared three times in different contexts.

The post quiz consisted of three parts. The first part was a vocabulary task in which the participants were requested to choose the best definition of the underlined words from four given choices. The second part covered the strategies that the participants used to guess the unknown words while reading the text. In this part, the participants were expected to choose the strategies they employed in reading the text and provide some information about the other strategies they used when reading the text except the ones already included in this part. The last part involved three questions about the identification of the new words in the text, including or excluding the underlined words and the incidental learning of any new words from the text.

The level of context support had been examined by researcher Tim Roskams. He asked 6 native competent speakers of English to infer the words in a gap cloze. Thus it is confirmed that "this is of limited use in estimating guess ability for the L2 readers as the types of clues that L1 readers use (e.g. collocation) are often unavailable to L2 readers" (Roskams ,2005, p. 73).

\section{Procedures}

The participants were presented with a task sheet that consisted of the text in which 12 target words were underlined and the post quiz which comprised of three parts. After finishing reading the text, they were then asked to do the Post Quiz. The first part was the vocabulary task in which they were requested to choose the best definition of the underlined words from four given definitions. In the second part that involved the strategies they used to guess the unknown words while reading, they were expected to choose the strategies they employed in reading the text and provide some information about the other strategies they used except the ones listed in this part. The last part included three questions 
(see Appendix A). In this part, they were expected to answer questions whether they came across any new words in the text, whether they encountered other unknown word besides the underlined ones and whether they had learned any new words from the text. As for the second and the last question, they were asked to list the unknown words they found and the words that had been learned from the text. Almost all the Filipino graduate students finished the reading and the post quiz within 10- 15 minutes. Most of the Chinese graduate students did it within 15-25 minutes. Some of them did the task at home and gave the task sheets to the researcher one or more days later.

\section{Data Analysis}

Data were answers collected from the task sheets that were used to examine and assess the inferring strategies that the participants employed in reading the text. Mean (see Table 1) was applied to investigate what strategies or what inferencing strategies the participants utilized in reading the text. The comparison of the differences of the lexical inferencing strategies was produced by examining the mean of the lexical inferencing strategies used by the Filipino and the Chinese participants. The statistic means of mean and the standard deviation (see Table 2) were applied to illustrate the difference and discrepancy in using lexical inferring strategies to figure out the meanings of the underlined words in the text between the Filipino and the Chinese participants by comparing incorrect understanding of these underline words between the two groups of the graduate Students. Mean was used to disclose the number of the new words that the participants incidentally learned from the text (see Table 5).

\section{RESULTS}

TABLE 1 .

LEXICAL INFERENCING STRATEGIES FOR UNKNOWN WORDS

\begin{tabular}{|c|c|c|c|c|}
\hline \multirow[t]{2}{*}{ Employed Strategies } & \multicolumn{2}{|c|}{$\begin{array}{l}\text { Filipino graduate students } \\
(\mathrm{N}=17)\end{array}$} & \multicolumn{2}{|c|}{$\begin{array}{l}\text { Chinese graduate students } \\
(\mathrm{N}=17)\end{array}$} \\
\hline & $\mathrm{N}$ & mean & $\mathrm{N}$ & mean \\
\hline Guess using local (sentence-level) context & 10 & 58.82 & 12 & 70.59 \\
\hline Guess using association or collocation knowledge (i.e. a clue word) & 11 & 64.71 & 11 & 64.71 \\
\hline Guess using syntactic knowledge & 6 & 35.29 & 5 & 29.41 \\
\hline Guess using visual form (similarity or morphological understanding) & 4 & 23.53 & 9 & 52.94 \\
\hline Guess using extra textual (thematic or world) knowledge & 9 & 52.94 & 7 & 41.18 \\
\hline $\begin{array}{l}\text { Guess using discourse context i.e. outside the sentence in which the } \\
\text { word occurred (using forward or backward context) }\end{array}$ & 5 & 29.41 & 14 & 82.35 \\
\hline $\begin{array}{l}\text { Other strategies or skills used to deal with the unknown words in the } \\
\text { article (such as consult a dictionary) }\end{array}$ & & & 3 & 17.65 \\
\hline
\end{tabular}

Table 1 presents the mean of strategies that the Filipino graduate students and the Chinese graduate students used to deal with the unknown words encountered in reading the text. As shown in Table 1, almost all the participants used the lexical inferencing strategies. Only three of the Chinese graduate students used the strategy of consulting the dictionary. There was similarity in the strategy adoption between them. The same mean of the number of the students (64.71) was observed in choosing the lexical strategy of guessing unknown words by using association or collocation knowledge. Association refers to the word association that a given word is associated with the first word that comes to one's mind and is connected with the given word, such as an antonym, synonym and so on. Collocation means that certain words often co-occur and they are often in a syntactic relation such as verb-object ('take care'), and in a lexical relation such as antonym, synonym and superordinate (such as furniture and table, chair, sofa, etc.) and so on. It seemed that word association and collocation were most preferred by both the Filipino graduate students and the Chinese graduate students due to the fact that it was the easiest and commonest way to guess unknown words. The other strategies preferred by both the Filipino graduate students and the Chinese graduate students were guessing using local (sentence-level) context, guessing using extra textual (thematic or world knowledge) and guessing using syntactic knowledge. Local (sentence-level) context means sentence-level grammar that "learners frequently used their knowledge of relationships among sentence components including word-class information, often signaled by word order, in dealing with unknown nouns and adjective" (Paribarht, \& Wesche, 1999, p. 207). Extra textual (thematic or world knowledge) refers to the familiarity with the topic and the content of the reading material, which can help readers to infer unknown words. Syntactic knowledge involves sentence structures and word order also can help readers to guess the meanings of unknown words. More participants from both countries in this study chose the four strategies explained above compared with the other strategies. However, there were some discrepancies between the strategies employed by the Filipino graduate students and the Chinese graduate students. From Table 1, some differences were found in using the lexical inferencing strategies between the Filipino graduate students and the Chinese graduate students. The Chinese graduate students in making use of strategy of guessing using discourse context, that is, using outside the sentence in which the word occurred (using forward or backward context) outnumbered $(82.35 \%)$ the Filipino graduate students (29.41\%). The number of the Chinese graduate students was much larger than that of the Filipino graduate students in employing strategies of guessing using local (sentence-level) context (70.59\% vs 58.82\%) and guessing using visual form that refers to applying word derivations such as prefixes and suffixes as well as grammatical inflections $(52.94 \%$ vs $23.53 \%$ ). However, in using syntactic knowledge and extra textual (thematic or world) knowledge, more Filipino 
graduate students (35.29\% in using syntactic knowledge and $52.94 \%$ in using extra textual knowledge) than the Chinese graduate students $(29.41 \%$ in syntactic knowledge and $41.18 \%$ in extra textual knowledge). No Filipino graduate students were found to use other non-lexical inferencing strategies in this study. Table 1 seemed to indicate that the Chinese graduate students preferred using lexical inferencing strategies more to deal with unknown words than the Filipino graduate students did while reading in English.

TABLE 2 .

COMPARISON OF INITIAL IDENTIFICATION OF WORDS IN READING BETWEEN THE FILIPINO GRADUATE STUDENTS AND THE CHINESE GRADUATE STUDENTS

\begin{tabular}{|c|c|c|c|c|c|c|}
\hline \multirow[t]{2}{*}{$\mathrm{N}=17$} & \multicolumn{2}{|c|}{$\begin{array}{l}\text { No. of unknown words incorrectly } \\
\text { understood by individual student }\end{array}$} & \multicolumn{4}{|c|}{$\begin{array}{l}\text { Response to Question } 1 \text { about } \\
\text { word visual recognition }\end{array}$} \\
\hline & Filipino students & Chinese students & \multicolumn{2}{|c|}{$\begin{array}{l}\text { Filipino students } \\
\qquad \mathrm{N}=17\end{array}$} & \multicolumn{2}{|c|}{$\begin{array}{l}\text { Chinese students } \\
\mathrm{N}=17\end{array}$} \\
\hline 1 & 2 & 2 & \multicolumn{2}{|l|}{ Yes } & \multicolumn{2}{|l|}{ Yes } \\
\hline 2 & 2 & 1 & \multicolumn{2}{|l|}{ Yes } & \multicolumn{2}{|l|}{ Yes } \\
\hline 3 & 1 & 7 & \multicolumn{2}{|l|}{ Yes } & \multicolumn{2}{|l|}{ Yes } \\
\hline 4 & 1 & 2 & \multicolumn{2}{|l|}{ No } & \multicolumn{2}{|l|}{ Yes } \\
\hline 5 & 3 & 4 & \multicolumn{2}{|l|}{ Yes } & \multicolumn{2}{|l|}{ Yes } \\
\hline 6 & 1 & 3 & \multicolumn{2}{|l|}{ No } & \multicolumn{2}{|l|}{ Yes } \\
\hline 7 & 1 & 3 & \multicolumn{2}{|l|}{ No } & \multicolumn{2}{|l|}{ Yes } \\
\hline 8 & 6 & 6 & \multicolumn{2}{|l|}{ No } & \multicolumn{2}{|l|}{ Yes } \\
\hline 9 & 2 & 6 & \multicolumn{2}{|l|}{ Yes } & \multicolumn{2}{|l|}{ Yes } \\
\hline 10 & 5 & 2 & \multicolumn{2}{|l|}{ No } & \multicolumn{2}{|l|}{ Yes } \\
\hline 11 & 3 & 2 & \multicolumn{2}{|l|}{ No } & \multicolumn{2}{|l|}{ Yes } \\
\hline 12 & 2 & 3 & \multicolumn{2}{|l|}{ No } & \multicolumn{2}{|l|}{ Yes } \\
\hline 13 & 1 & 3 & \multicolumn{2}{|l|}{ No } & \multicolumn{2}{|l|}{ Yes } \\
\hline 14 & 1 & 3 & \multicolumn{2}{|l|}{ No } & \multicolumn{2}{|l|}{ No } \\
\hline 15 & 1 & 2 & \multicolumn{2}{|l|}{ No } & \multicolumn{2}{|l|}{ No } \\
\hline 16 & 2 & 3 & \multicolumn{2}{|l|}{ No } & No & \\
\hline 17 & 4 & 8 & No & & No & \\
\hline & $\begin{array}{l}\text { Total no. of } \\
\text { incorrect inferred } \\
\text { words }(38)\end{array}$ & $\begin{array}{l}\text { Total no. of } \\
\text { incorrect inferred } \\
\text { words }(60)\end{array}$ & $\begin{array}{l}\text { mean of } \\
\text { 'yes' } \\
29.41\end{array}$ & $\begin{array}{l}\text { mean of } \\
\text { 'No' } \\
70.59\end{array}$ & $\begin{array}{l}\text { mean of } \\
\text { 'yes' } \\
76.47\end{array}$ & $\begin{array}{l}\text { mean of } \\
\text { 'No' } \\
23.53\end{array}$ \\
\hline
\end{tabular}

Table 2 demonstrated the comparison of initial identification of words and the number of the words incorrectly understood or inferred by individual Filipino graduate students and Chinese graduate students in reading the text. Initial identification of words is one of the lexical inferencing strategies in accordance with researcher Roskams (2005). It refers to word visual recognition, including three conceptions. First, students cannot identify the unknown word to them. Second, assume that they can identify the form of the known words but have forgotten in reading a text or never knew the meanings of the words and assume that they can recognize the form and know the meanings of the words. From Table 2, it can be found that $70.59 \%$ of the Filipino graduate students failed to recognize all the unknown words because they did not correctly understood all the new words in the text. Almost all the Filipino students who reported that they did not encounter any unknown words made mistakes in understanding the new words. It was worth noting that students No. 8, No. 10 and No. 17 who said that they did not come across any unknown words in the text made more wrong inferences of these unknown words (6, 5 and 4 wrong inferences respectively made by the three students). Similar results were found on some of Chinese graduate students. Chinese student No. 17 who reported that he/she did not encounter any unknown words failed to get 8 unknown words correctly understood. The other Chinese students No. 3, 8 and 9 made more than half wrong inferences out of 12 underlined words in the text. One of the main reasons why these students thought there were no unknown words for them may be that they must assume they recognized the form and the meaning of these unknown words without checking them in the context of the text. Conversely, the Chinese graduate students $(76.47 \%)$ could recognize the unknown words, but they did not successfully infer the meaning of all the unknown word from the context. Compared with the Filipino graduate students (a total of 38 incorrectly understood words), the Chinese graduate students made more mistakes (a total of 60) in inferring unknown words they encountered in reading English.

TABLE 3

COMPARISON OF INCORRECT UNDERSTANDING OF THE UNKNOWN WORDS BETWEEN THE FILIPINO GRADUATE STUDENTS AND THE CHINESE GRADUATE STUDENTS

\begin{tabular}{|c|c|c|}
\hline Means & Filipino students & Chinese students \\
\hline mean & 2.235294 & 3.529412 \\
\hline STDEV & 1.521899 & 2.003673 \\
\hline
\end{tabular}

Table 3 shows the comparison of incorrect understanding of the unknown words between the Filipino graduate students and Chinese graduate students. As revealed in Table 3, the number of the incorrect understanding of the unknown words by Chinesestudents was larger than the Filipino students, and the discrepancy of the Chinese students' level of vocabulary knowledge is much larger $(\mathrm{SD}=2.0036)$ than that of the Filipino students $(\mathrm{SD}=1.5219)$. Referred to 
Table 2, the number of the unsuccessful inferred word by the Chinese students ranged from 1 to 8 . One of the students misunderstood eight unknown words, which meant that he/she could not infer $66.67 \%$ of the unknown words; the other student misunderstood seven, about $58.33 \%$ of the unknown words in the task. Another two students failed to infer six unknown words $(50 \%)$ from the text. By contrast, the Filipino students had more words correctly understood. Only one student got $6(50 \%)$ unknown word incorrectly inferred.

TABLE 4

COMPARISON OF THE INFLUENCE OF WORD OCCURRENCE ON LEXICAL INFERENCING

\begin{tabular}{|l|l|lc|lc|}
\hline \multirow{2}{*}{ Words } & \multirow{2}{*}{$\begin{array}{l}\text { Occurrence in } \\
\text { the text }\end{array}$} & \multicolumn{2}{|l|}{ Filipino graduate students } & \multicolumn{2}{l|}{ Chinese graduate students } \\
\cline { 3 - 6 } & 3 & $\mathrm{~N}$ & mean & $\mathrm{N}$ & mean \\
\hline Critical & 3 & 17 & 100 & 13 & 76.47 \\
\hline Drastic & 1 & 14 & 82.35 & 11 & 64.71 \\
\hline Deprivation & 2 & 17 & 100 & 12 & 70.59 \\
\hline mop up & 1 & 10 & 58.82 & 8 & 47.06 \\
\hline Milestone & 1 & 16 & 94.12 & 15 & 88.24 \\
\hline Quotient & 1 & 15 & 88.24 & 15 & 88.24 \\
\hline Utter & 1 & 3 & 17.65 & 7 & 41.18 \\
\hline Hubbub & 1 & 12 & 70.59 & 13 & 76.47 \\
\hline Cue & 3 & 13 & 76.47 & 8 & 47.06 \\
\hline Babbling & 1 & 17 & 100 & 14 & 82.35 \\
\hline Clinging & 1 & 16 & 94.12 & 12 & 70.59 \\
\hline Trigger & 2 & 17 & 100 & 15 & 88.24 \\
\hline
\end{tabular}

Table 4 presents the comparison of the influence of word occurrence on lexical inferencing. The results presented in Table 4 indicated that the occurrence of unknown words seemed to have an impact on the lexical inferencing used by the Filipino graduate students. As we can see, "critical" appeared three times, "deprivation' and "trigger" twice in the text; as a result, all the Filipino graduate students successfully obtained the meanings of these possibly unknown words. About $76.47 \%$ of the Filipino graduate students correctly inferred the words "cue" that appeared three times in the text. Nevertheless, the occurrence of the target words seemed not to help the Chinese graduate students infer the meanings of these high-occurrence words compared with the other words of low occurrence. Only $47.06 \%$ of the Chinese graduate students could figure out the meaning of the word "cue" compared with the Filipino graduate students. The mean of the correct guess of the other three high-occurrence word "critical", "deprivation' and "trigger" was much lower than that of the Filipino graduate students.

Table 5 shows the comparison of the words reported to be learned incidentally by lexical inferencing in reading between the Filipino and the Chinese Graduate Students. Incidental vocabulary learning refers to unconsciously gaining some new words in reading a text. "Such learning has been called "incidental" because it occurs as learners are focused on something other than word learning itself" (Paribarht, \& Wesche, 1999, p. 196). The results shown in Table 5 demonstrated that to some extent, the Chinese graduate students seemed to gain some new words through incidental learning when using lexical inferencing to deal with these unknown words. All the target words were reported to be learned to some extent by Chinese participants. It is worth noting that $64.71 \%$ of the Chinese graduate students declared that they had learned the unknown word "hubbub" when inferring the meaning of the word from the context. Similarly, $35.29 \%$ of the Filipino graduate students said that they gained the word too. Besides the underlined word in the text, it was found that the other words declared by Chinese participants as unknown such as infant, starve ,discouraged and nonverbal were also learned by some Chinese participants in this study. Unsurprisingly, the Filipino graduate students did not report that they had learned any other word except "hubbub" and "mop up". As to the other words, none of the Filipino graduate students reported that they had learned any of them. For most of the Filipino graduate students, the main reason may be that they assumed these words were not the unknown words to them (see Table 2) and they had already grasped them. However, those who claimed that they thought some of the underlined words were unknown words did not report that they had learned any of them. It seemed that the Filipino graduate students were not benefited from reading in incidental vocabulary learning in this study. 
TABLE 5.

COMPARISON OF THE WORDS REPORTED TO BE LEARNED INCIDENTALLY BY LEXICAL INFERENCING IN READING BETWEEN THE FILIPINO AND THE Chinese GRAduATE STUdENTS

\begin{tabular}{|c|c|c|c|c|}
\hline \multirow[t]{2}{*}{ Words } & \multicolumn{2}{|c|}{$\begin{array}{l}\text { the Filipino graduate students } \\
\qquad \mathrm{N}=17\end{array}$} & \multicolumn{2}{|c|}{$\begin{array}{l}\text { the Chinese Graduate Students } \\
\qquad \mathrm{N}=17\end{array}$} \\
\hline & $\begin{array}{l}\text { mean of } \\
\text { correctly } \\
\text { understood }\end{array}$ & $\begin{array}{l}\text { mean of } \\
\text { incidental } \\
\text { learning }\end{array}$ & $\begin{array}{l}\text { mean of } \\
\text { correctly } \\
\text { understood }\end{array}$ & $\begin{array}{l}\text { mean of } \\
\text { incidental } \\
\text { learning }\end{array}$ \\
\hline Critical & 100 & 0 & 76.47 & 17.65 \\
\hline Drastic & 82.35 & 0 & 64.71 & 35.29 \\
\hline Deprivation & 100 & 0 & 70.59 & 29.41 \\
\hline Mop up & 58.82 & 5.88 & 47.06 & 23.53 \\
\hline Milestone & 94.12 & 0 & 88.24 & 17.65 \\
\hline Quotient & 88.24 & 0 & 88.24 & 35.29 \\
\hline Utter & 17.65 & 0 & 41.18 & 23.53 \\
\hline Hubbub & 70.59 & 35.29 & 76.47 & 64.71 \\
\hline Cue & 76.47 & 0 & 47.06 & 23.53 \\
\hline Babbling & 100 & 0 & 82.35 & 41.18 \\
\hline Clinging & 94.12 & 0 & 70.59 & 17.65 \\
\hline Trigger & 100 & 0 & 88.24 & 11.76 \\
\hline Infant & & 0 & & 5.88 \\
\hline Starve & & 0 & & 5.88 \\
\hline Discouraged & & 0 & & 5.88 \\
\hline Nonverbal & & 0 & & 5.88 \\
\hline
\end{tabular}

\section{DISCUSSION}

\section{A. Lexical Inferencing Strategies}

The first three research questions involved the lexical strategies employed by the Filipino graduate students and the Chinese graduate students. As for the first research question whether the Chinese graduate students and the Filipino graduate students in this study employed lexical inferencing to deal with unknown words in reading, the results in this study provided a confirmative answer. From Table 1, it was noticed that almost all the participants used the lexical inferencing strategies. Only three of the Chinese graduate students reported themselves to consult the dictionary for the unknown words while reading the text besides the use of the inference strategies. Both the Filipino graduate students and the Chinese graduate students preferred the same strategies for dealing with lexical problems while reading. It was obvious that inferencing was the most common strategy used by the advanced learners in a university setting to deal with lexical problems encountered in reading English. Compared with the Filipino graduate students, it seemed that the Chinese graduate students preferred using lexical strategies more to deal with unknown words. The reason may be that compared to English as a second language (ESL) learners, EFL learners often lack an adequate amount of oral or written input; consequently, it is very difficult for them to acquire the vocabulary around them so that they need to compensate for enlarging vocabulary by reading more. In EFL classroom reading instruction such as in China, learners are trained to use different strategies to solving the lexical problems, and inferring unknown words from the context is one of the important strategies they are often taught to use.

As to the second research question of what inferring strategies the Chinese graduate students and the Filipino graduate students used to deal with unknown words in reading, Table 1 supplies the answers. The strategy of guessing unknown words by using association or collocation knowledge, guessing using local (sentence-level) context, guessing using extra textual (thematic or world knowledge) and guessing using syntactic knowledge were preferred by both the Filipino graduate students and the Chinese graduate students, which is consistent with the results of study done by Paribakht and Wesche (1999). Besides, forward and backward strategy and association or collocation knowledge strategy were most used by the Chinese graduate students. It was displayed that the text had enough clues to help the participants to infer the meaning of these unknown words. For example, the word "drastic" can be guessed using forward and backward strategy and association or collocation knowledge strategy. The clue in the forward context may be "a critical period of life can be starved and damaged" and the backward context "died". The word "died" and "drastic" belong to the collocation and Table 3 shows that most of the participants successfully inferred the meaning of this word. However, it was strange that most of the Filipino graduate students and the Chinese graduate students both failed to use the two strategies applied in dealing with "drastic" to infer the meaning of the word "cue". This failure may be caused by the possibility that the participants assumed that they knew the meaning of a word in context and this assumption was associated with less checking of the word in its context. Only $47.06 \%$ of the Chinese graduate students 
and $76.47 \%$ of the Filipino graduate students figured out the meaning of the word. It was worth noting that extra textual knowledge including semantic and world knowledge was of great importance in helping inferring unknown words. From Table 1, the Filipino graduate students were observed to use this strategy more than the Chinese graduate students and most of them succeeded in inferring the unknown words in most of the cases, which may be due to the fact that all the Filipino participants were the graduate students studying Teaching English Language so that most of them should be familiar with the topic of the text--critical period of language learning that is a vital conception in the development of language in the foundation of linguistics. By contrast to the Filipino graduate students, the Chinese graduate students seemed to use less extra textual knowledge to work out the meanings of the unknown words, which may be due to lack of the knowledge talked about in the text because seven of them were not the students of MATEL and they were not familiar with the topic.

With respect to the third research question about whether there was any difference in the employment of inferring strategies between the Chinese graduate students and the Filipino graduate students and if yes, what the difference was, there were notable distinctions in using inferring strategies between the Filipino graduate students and the Chinese graduate students. First, as far as choosing lexical inferenceing strategies was concerned, the Chinese graduate students appeared to prefer making use of strategy of guessing using discourse context, that is, using outside the sentence in which the word occurred, guessing using local (sentence-level) context and guessing using visual form (similarity or morphological understanding), which may be due to the fact that in Chinese classroom instruction, learners are often introduced and trained to use the strategies of using forward and backward clues, the word-form knowledge and the grammar analysis of the sentences to infer the meaning of a word. Differently, in using syntactic knowledge and extra textual (thematic or world) knowledge, more Filipino graduate students than the Chinese graduate students chose to utilize this strategy, which was likely that the familiarity of the topic of the text assisted them to guess the unknown words easily without the necessity of using other strategies. Thus it was not surprising to find that no Filipino graduate students were found to use other non-lexical inferencing strategies in this study. From Table 1, it can be concluded that the Chinese graduate students preferred using lexical strategies more to deal with unknown words than the Filipino graduate students did while reading in English. Second, Table 2 disclosed that the Filipino graduate students and the Chinese graduate students behaved differently in recognizing unknown words. It was implied that the cause which made the Filipino graduate students fail to recognize all the unknown words may be that they assumed they recognized the form and the meaning of the unknown words. This result agreed with that of study conducted by Huckin and Bloch (1993). One obvious cause of failure was that the readers claimed to know a word but, in fact, did not know an appropriate meaning for the text. Another was that they might force a meaning (often from assumed knowledge or association) into the text even where this meaning was clearly not appropriate. Although the Chinese graduate students could recognize the unknown words, they did not successfully infer the meanings of some unknown words from the context. Compared with the Filipino graduate students, the Chinese graduate students made more wrong inferences of unknown words they encountered in reading English. One of the reasons may also be that they assumed to know the word but, in fact, did not figure out the correct meaning for the text. Some of the participants may not bother themselves to reread the text and use the context clues to check their inference of the word. This may be the main obstacle to prevent the participants from using proper inferencing strategies to work out the meaning of words. Third, as shown in Table 3, it seemed that more unsuccessful inference of the unknown words was made by Chinese students than did by the Filipino students, and the discrepancy of the Chinese students' level of vocabulary knowledge is much larger $(\mathrm{SD}=2.0036)$ than that of the Filipino students $(\mathrm{SD}=1.5219)$. The number of the unsuccessful inferred word by the Chinese students ranged from 1 to 8 . This may be caused by the very limited vocabulary knowledge because some participants found some other unknown words in the text besides the underlined ones. Too many unknown words may hinder the Chinese participants from understanding the text and making correct inference to the unknown words even though the text provided obvious clues. Fourth, some obvious difference could be discovered from Table 4 that exhibited the influence of the occurrence of unknown words on lexical inferencing. It seemed that the occurrence of unknown words seemed to have an influence on the lexical inferencing used by the Filipino graduate students but not on the inferencing strategies by the Chinese graduate students. The occurrence of high-frequent unknown words seemed unhelpful to the Chinese participants in the correct inferences of these unknown words, which may have the reasons that some such words occurred in different contexts and had a different meaning in each context. Finally, the Chinese graduate students seemed to gain some words through incidental learning when using lexical inferencing to deal with these unknown words, while the Filipino graduate students did not report that they had learned any other word except "hubbub". The most possible reason was that they assumed they did not regard these words as unknown ones so that they paid no attention to these words or they assumed they had already gained them.

\section{B. Evidence for Incidental Vocabulary Learning}

The fourth research question entailed the incidental vocabulary learning by lexical inferencing while reading between the Filipino Graduate Students and the Chinese Graduate Students. The results of this study did not permit an unequivocal affirmation. It only provided a little evidence for incidental vocabulary learning. From Table 4, it was observed that to some extent, the Chinese graduate students seemed to gain some words through incidental learning when using lexical inferencing to deal with these unknown words. Sixty-four point seven one percent $(64.71 \%)$ of the Chinese graduate students declared that they had learned the unknown word "hubbub" when inferring the meaning of 
the word from the context. Thirty-five point two nine $(35.29 \%)$ of the Filipino graduate students claimed that they gained this word too. Besides the underlined word in the text, it was found that the other words declared by Chinese participants as unknown words such as infant, starve, discouraged and nonverbal were also learned by some participants in this study. However, it was true that this study did not provide further evidence to confirm that these words were actually grasped by the participants. Maybe further study is needed to examine whether unknown words that were reported to be gained incidentally in referring their meanings are acquired actually by readers or not. Paribakht, et al. (1999, p. 215) pointed out that "vocabulary learning outcomes from reading will always be unpredictable because different learners attend to different words, invest different levels of effort into figuring out the meanings of unknown words while per tendency to use particular strategies that can help them to successfully solve their lexical problems". Therefore, the results of this study imply that attending to unknown vocabulary when reading for comprehension seemed to help the participants to develop their vocabulary in increasing vocabulary breadth but not developing fluency with unknown vocabulary because it was displayed that the correct lexical inference did not always happen in this study.

\section{CONCLUSION}

This study examined the lexical inferencing strategies used by the Filipino graduate students and the Chinese graduate students. Some conclusions can be drawn from this study. Firstly, it was confirmed by the results of this study that both the Filipino graduate students and the Chinese graduate students did employ the lexical inferencing strategies while reading English. Secondly, it seemed that the Chinese graduate students favored using lexical strategies more to deal with unknown words than the Filipino graduate students. Moreover, the strategy of guessing unknown words by using association or collocation knowledge, guessing using local (sentence- level) context, guessing using extra textual (thematic or world knowledge) and guessing using syntactic knowledge were preferred by both the Filipino graduate students and the Chinese graduate students. It was found that forward and backward strategy and association or collocation knowledge strategy were most used by the Chinese graduate students. Thirdly, there were notable distinctions in using inferring strategies between the Filipino graduate students and the Chinese graduate students. The Chinese graduate students seemed to like using strategy of guessing using discourse context, local (sentence-level) context and visual form (similarity or morphological understanding), while syntactic knowledge and extra textual (thematic or world) knowledge were preferred by more Filipino graduate students than the Chinese graduate students. Fourthly, it is very dangerous for readers to assume to know the word but, in fact, did not figure out the correct meaning for the text because this may lead to the wrong interpretations of the words and thus make it difficult to understand a text, even miscomprehending a text. Fifth, it seemed that the high-occurrence of unknown words were not beneficial to the Chinese participants in the correct inference of these unknown word meanings, if these words occurred in different contexts and had a different meaning in each context. Finally, as for the incidental vocabulary learning, the results of this study did not provide enough evidence. It seemed that attending to unknown vocabulary when reading for comprehension seemed to help the participants to get to know some unknown words but not completely gain the use of the words.

The findings of this study have implications for language teaching. First, since the results of this study exhibited that lexical inferencing strategies was the most common used strategies and they could affect the inference of a word's meaning, it is very important for teachers to train students, particularly, EFL learners, to use appropriate lexical inferencing strategies to deal with unknown words while reading because they are lack of opportunities to obtain words around them. The only way for EFL learners to learn English language and its vocabulary is reading as much as possible. Second, at the beginning of the classroom training of lexical referring strategies, a text with enough inference clues should be presented to learners to help them excel at applying these lexical inferring strategies to inferring unknown words in reading. Third, learners should be instructed to attend to those words that are key to understand the text even though they are assumed to be known words because they may have the different meanings in that text. The best way is to check the meaning of the word with context clues to infer its appropriate meaning. Fourth, advanced ESL and EFL learners like the participants in this study need to read more authentic reading materials to increase their vocabulary and reading comprehension since the lexical inferencing strategies seemed to have a positive influence on vocabulary learning. However, since the results of this study did not provide enough evidence that lexical inference could help to gain the vocabulary, teachers should provide systematic, explicit vocabulary instruction to help them to expand, consolidate and elaborate their new lexicons encountered in reading (Hunt, \& Beglar, 2005). Fifth, Ellis (1994) explained that new vocabulary can be acquired when learners negotiate the meaning of unknown word by joining in classroom discussions which may draw learners' attention to these words and offer chances to them to negotiate the meanings of these words and practice using them. Classroom discussions can lead to vocabulary gains for both those who lead the discussion and those who just listen to the discussion. Therefore, in classroom reading instruction, teachers should provide as many opportunities as possible to learners to have classroom discussions. Lastly, correct vocabulary inferences may need to combine several strategies such as combining inferencing with dictionary use (especially for EFL learners), using the word productively in original contexts, rereading the passage and so on.

However, this study has two limitations. First, the questions that involved the lexical inferencing strategies should be put below each underlined word in the vocabulary task in the post quiz so that the detailed information about the 
concrete strategies used to infer the meaning of each unknown word could be obtained. Second, only written data from the task sheets were analyzed. Individual interview should be done to get more information on how the participants make lexical inference while reading.

\section{ACKNOWLEDGEMENTS}

I would like to thank my professor Dr. Remedios Z. Miciano for her guidance and instructional comments in this study. My thanks also go to the Filipino graduate students and the Chinese graduate students involved in this study.

\section{APPENDIX}

Task Sheets

Part I: (Adapted from Roskams, T., 2005)

Age Gender

Course of study at present university

The years that have been exposed to English

Part II: Read the following text and do the vocabulary task.

Directions: Text with words to be inferred highlighted by occurrence and part of speech The words to be inferred are followed by a number which indicates the occurrence in the text, a notation ( $\mathrm{N}=$ noun $\mathrm{V}=\mathrm{verb}$ or gerund, $\mathrm{A}=\mathrm{adjective})$. Underlined words are those which were underlined in the text presented to students for inferring).

Our First Words is language, like food, a basic human need without which a child at a critical $(1$, a) period of life can be starved and damaged? Judging from the drastic $(1$, a) experiment of Frederick II in the thirteenth century it may be. Hoping to discover what language a child would speak if he heard no mother tongue he told the nurses to keep silent. All the infants died before the first year. But clearly there was more than language deprivation $(1, n)$ here. What was missing was good mothering. Without good mothering, in the first year of life especially, the capacity to survive is seriously affected.

Today no such drastic (2, a) deprivation (2. n) exists as that ordered by Frederick. Nevertheless, some children are still backward in speaking. Most often the reason for this is that the mother is insensitive to the cues $(1, n)$ and signals of the infant, whose brain is programmed to mop up $(1, v)$ language rapidly. There are critical $(2$, a) times, it seems, when children learn more rapidly. If these sensitive periods are neglected, the ideal time for acquiring skills passes and they might never be learned so easily again.

A bird learns to sing and to fly rapidly at the right time, but the process is slow and hard once the critical (3, a) stage has passed. Linguists suggest that speech milestones $(1, n)$ are reached in a fixed sequence and at a constant age, but there are cases where speech has started late in a child who eventually turns out to be of high IQ (Intelligence Ouotient (1. n)). At twelve weeks a baby smiles and utters (1, v ) vowel-like sounds; at twelve months he can speak simple words and understand simple commands; at eighteen months he has a vocabulary from three to fifty words. At three he knows about 1000 words which he can put into sentences, and at four his language differs from that of his parents in style rather than grammar.

Recent evidence suggests that an infant is born with the capacity to speak. What is special about Man's brain, compared with that of the monkey, is the complex system which enables a child to connect the sight and feel of, say, a teddy-bear with the sound pattern 'teddy-bear'. And even more incredible is the young brain's ability to pick out an order in language from the hubbub $(1, n)$ of sound around him, to analyse, to combine and recombine the parts of a language in novel ways.

But the speech has to be triggered (2,v), and this depends in the interaction between the mother and the child, where the mother recognizes the cues $(2, n)$ and signals in the child's babbling $(1, n)$, clinging $(1, n)$, grasping, crying, smiling, and responds to them.

Insensitivity of the mother to these signals dulls the interaction because the child gets discouraged and sends out only the obvious signals. Sensitivity to the child's non- erbal cues $(3, n)$ is essential to the growth and development of language.

(From an article which originally appeared in The Observer and reprinted in Maley, A and Duff, A. (1986). Beyond words: Certificate reading and listening skills. Cambridge University Press)

The Post Quiz

Directions: Please work through the following list and put a circle around the best definition of the underlined word.

This is not a test so please do not use a dictionary or other text to assist you.

If you do not have any idea about the meaning of a word, please leave it blank.

1. A critical period of life:

a) slow

b) very important

c) unfortunate

d) exciting
2.A drastic experiment:

a) violent (causing hurt)

b) very important

c) exciting

d) to be published (in a journal) 
3. Deprivation of food

a) excessive amount

b) keeping separate

c) special delivery

d) delicious kind

5. A milestone in speech development

a) slow growth

b) important point

c) psychological test

d) lateness

7. Utters a sound:

a) repeat

b) speaks

c) prevents

d) tries to make

9. A trigger to action:

a) causing violence

b) causing a start

c) causing a stop

d) something instead of

11. Clinging behaviour:

loving

angry

full of wonder

holding closely
4. To mop up language:

a) absorb

b) clean up

c) forget

d) study

6. Intelligence Quotient

a) lack

b) result of division

c) measurement

d) electronic machine

8. A hubbub of sound:

a) noisy confusion

b) absence

c) pleasant kind

d) hard to hear kind

10. A cue in a child's behavior:

a) causing anger

b) badness

c) suggestion

d) new stage

12. A trigger to action:

a) causing violence

b) causing a start

c) causing a stop

d) something instead of

Part III. Answer the following questions that cover the strategies or skills you employed in dealing with the unknown words in the text.

Which strategies do you employed to deal with the unknown words in the text? Put a circle around the number of your choice. You can choose more than one strategies.

Guess using local (sentence level) context

Guess using association or collocation knowledge (i.e. a clue word)

Guess using syntactic knowledge

Guess using visual form (similarity or morphological understanding)

Guess using extra textual (thematic or world) knowledge

Guess using discourse context i.e. outside the sentence in which the word occurred (using forward or backward context)

You used the other strategies or skills that were not listed above to deal with the unknown words in the article, they are

Part IV. Answer the following questions.

You did not encounter any unknown words in the article, did you?

2) Did you encounter other unknown words in the article besides the underlined ones? If yes, what are they?

3) Have you learned any new words from the article? If yes, what are they?

\section{REFERENCES}

[1] Carnine, D., Kameenui, E. J., \& Coyle, G. (1984). Utilization of contextual information in determining the meaning of unfamiliar words. Reading Research Quarterly 19, 188-204.

[2] Chern, C.L. (1993). Chinese students word solving strategies in reading in English. In Huckin, T., Haynes, M., and Coady, J. (1993) (eds.). Second Language Reading and Vocabulary Learning (67-85). New Jersey: Ablex Publishing Corporation.

[3] Coady, J. (1997). L2 vocabulary acquisition: A synthesis of the research. In J. Coady \& T. Huckin (eds.), Second language vocabulary acquisition, 273-290. New York: Cambridge University Press.

[4] DeBot, K., Paribakht, T. \& Wesche, M. (1997). towards lexical processing model for the study of second language vocabulary acquisition: Evidence from ESL reading. Studies in Second Language Acquisition 19, 309-329

[5] Ellis, R (1994). Factors in the incidental acquisition of second language vocabulary from oral input: A review essay. Applied Language Learning 5, 1-32.

[6] Fukkink, R. G., Blok, H., \& De Glopper, K. (2001). Deriving word meaning from written context: A multicomponential skill. Language Learning 51, 477-96.

[7] Haastrup, K. (1991). Lexical inferencing procedures or talking about words. Tubingen: Gunter Narr.

[8] Haynes, M. (1984). Patterns and perils of guessing in second language reading. In Huckin, T., Haynes, M., and Coady, J. (1993) 
(eds.). Second Language Reading and Vocabulary Learning. Ablex Publishing Corporation, Norwood, New Jersey, 46-64.

[9] Hirsh, D. \& Nation, P. (1992). What vocabulary size is needed to read unsimplified texts for pleasure? Reading in a Foreign Language 8, 689-696.

[10] Huckin, T. \& Bloch, J. (1993) Strategies for inferring word meaning in context: A cognitive model. In Huckin, T., Haynes, M., and Coady, J. (1993). (Eds.) Second Language Reading and Vocabulary Learning. Ablex Publishing Corporation, Norwood, New Jersey, 153-178.

[11] Hunt, A. \& Beglar, D. (2005). A framework for developing EFL reading vocabulary. Reading in a Foreign language, vol. 17. No. 1, Apr. 23-59. Retrieved from http://nflre.hawaii.edu. /rfl

[12] May, F. (2001). Unraveling the Seven Myths of Reading. Assessment and Intervention Practices for Counteracting their Effects. Boston: Allyn and Bacon, 107-139.

[13] Nagy, W., Herman, P., \& Anderson, R. (1985). Learning words from context. Reading Research Quarterly 20, $233-253$.

[14] Nation, I. S. P. (2001). Learning vocabulary in another language. Cambridge: Cambridge University Press.

[15] Nation, I.S.P., \& Coady, J. (1988). Vocabulary and reading. In R. Carter \& M. McCarthy (Eds.), Vocabulary and Language teaching (pp. 97-110). London: Longman.

[16] Paribakht. T. S. \& Wesche. M. (1999). Reading and "incidental" L2 vocabulary acquisition. Studies in Second Language Acquisition 21,195-224.

[17] Roskams, T. (2005). What's a guess worth? Chinese students' inferencing strategies For unknown words while reading, 65-102. Retrieved from: http://sunzi1.lib.hku.hk/hkjo/view/5/500048.pdf

[18] Stoller, F., \& Grabe, W. (1993). Implications for L2 vocabulary acquistion and instruction from L1 vocabulary research. In T. Huckin, M. Haynes, \& J. Coady (Eds.), Second language reading and vocabulary learning, 29-45. Norwood, NJ: Ablex.

Qiaoying Wang was born in Bijie of Guizhou, China. She received her M.A. degree in English language teaching from De La Salle University, the Philippines in 2005.

She is currently an associate professor in the Foreign Languages Department of Bijie University, Bijie, Guizhou, China. Two papers have been published these years. They are Classroom Interaction and Language Output published in the Vol.3, No.2, June 2010 of English Language Teaching and The Effects of Simplified and Elaborated Texts on Second Language Reading Comprehension: an Exploratory Study Published in the No. 2, 2005 of .VIGO International Journal of Applied Linguistics, Her research interests include English language learning \& teaching and English pragmatics. 